Katie A. Bernstein*

\title{
"Misunderstanding" and (mis)interpretation as strategic tools in intercultural interactions between preschool children
}

DOI 10.1515/applirev-2016-0021

Abstract: Misunderstandings in intercultural interactions are often taken as givens - unintentional side effects of coming to interactions with different languages and frames of reference - but also as givens that with enough effort and learning on the parts of participants might be repaired or even avoided. Researchers have warned, however, that assuming the intercultural-ness of these interactions to be the a priori cause of misunderstandings ignores possibly more complex, and less comfortable, explanations involving power relations and social identities. Drawing on data from a year-long ethnography of 11 Nepali- and Turkish-speaking children learning English in preschool in the United States, this paper argues that in some cases, it is less helpful to see intercultural-ness as a cause of misunderstanding than as an alibi for it. Through the lens of "strategic misunderstanding", this paper shows how one Englishspeaking student exploited the gap in language ability and in symbolic power between himself and an English language learner (ELL) peer in order to fake misunderstanding and thus accomplish his own social aims.

Keywords: intercultural communication, strategic misunderstanding, ascription of incompetence, positioning, children, preschool, ELL

\section{Introduction: Are intercultural} misunderstandings always intercultural...
or always real misunderstandings?

In his 1994 piece, "Intercultural or not? Beyond celebration of cultural differences in miscommunication analysis," Srikant Sarangi highlighted what he saw as one of the pitfalls of intercultural miscommunication work: Researchers, he said, had fallen into a circular trap. By classifying conversations as "intercultural" and

*Corresponding author: Katie A. Bernstein, Arizona State University, Tempe, AZ, USA, E-mail: kbernstein@asu.edu 
then studying the miscommunications that occurred therein, researchers set themselves up to find (unsurprisingly) that the source of misunderstandings was cultural difference, sometimes manifested in linguistic and paralinguistic difference, as in Gumperz' famous work on contextualization cues (1978, 1982, 1991). Sarangi argued that just because a misunderstanding occurs between people of different cultural backgrounds, one cannot unproblematically assume that culture is the cause. He underlined that, along with culture, speakers bring a host of other social identities, roles, and power relations to interactions, and in failing to examine these elements, researchers risk simplistic explanations based on cultural difference to the exclusion of less comfortable explanations involving power and inequality.

This paper examines one context of intercultural communication - a preschool classroom with a multilingual and multicultural student population bearing Sarangi's caution in mind: Rather than assuming that cultural and linguistic difference are the source of miscommunication, I argue that they can be an alibi for it, permitting students to (mis)understand and (mis)interpret in ways that would not happen between two speakers of the same language. This argument, however, rests not only on questioning the role of the "intercultural" in intercultural misunderstandings, but also on questioning the idea of "misunderstanding" itself. A look at the word "misunderstand" in the MerriamWebster dictionary produces the definition, “(v.) fail to interpret or understand (something) correctly" ("Misunderstand," n.d.). ("Fail” is defined as “(v.) be unsuccessful in achieving one’s goal." ["Fail," n.d].) A misunderstanding is therefore, by definition, an unintended and undesirable result, a lack of success at achieving the aim understanding. And indeed, in everyday talk, when misunderstandings occur, they are assumed to occur as mistakes or missteps, accidental outcomes other than what interlocutors intended.

Yet, some scholars have pointed out that misunderstandings might serve an interactional purpose and that they might therefore be carried out intentionally to strategic ends. In this paper, I draw on Cameron's (1998) and Hinnenkamp's (2003) ideas of "strategic misunderstanding" to show how preschool students employ misunderstanding and misinterpretation as intentional social tools in ways that are enabled, but not caused, by the intercultural context.

\section{Approach and organization of the paper}

Hinnenkamp lamented, "Rarely do we come across studies on misunderstandings as (pragma-) linguistic phenomenon in their own right. Even rarer are attempts to 
ground misunderstanding empirically. An absolute rarity is a real-life perspective on dialogue beyond experimental and fictional settings" (2003: 57). While the present paper is indeed empirically grounded, it is also theoretically grounded. It does not report the findings from a study of misunderstanding, in the sense that I set out to collect data on the topic and then catalogued and coded types of misunderstandings to produce this report. Rather this paper is an attempt to "think with theory" (Jackson and Mazzei 2012) about one particular interaction within the much larger data set. This interaction was one of a small handful of interactions that I flagged as "troubling." These extracts were troubling in that, at first glance, they seemed to be misunderstandings between English speakers and English learners, yet, unlike other misunderstandings in this classroom which interlocutors either worked to repair or simply ignored - these troubling misunderstandings appeared to be sustained by one of the speakers. This paper therefore represents a mutual "plugging in" (Jackson and Mazzei 2012) of data and theory to produce one potential reading as to what was occurring in this "troubling” data.

I begin, however, by describing the larger research project that this paper comes from, including the context, participants, and kinds of data collected. I then turn to a brief review of literature on legitimate misunderstandings and the ways that people, including preschoolers, draw attention to and resolve them. I illustrate this with an example from the present research context. I then explore, and theorize, another way of drawing attention to and resolving legitimate misunderstandings in the classroom in question: through the help of the third person who takes up the role of interpreter and "speaks for" the misunderstood speaker. Finally, having established what legitimate misunderstanding and repair look like in this multicultural, multilingual context, I outline Cameron's (1998) and Hinnenkamp's (2003) ideas of “strategic misunderstanding" and use their theories to tease apart one of the troubling extracts, which, on the surface, looked like a true misunderstanding, but which is better explained by seeing it as strategic use of misunderstanding and misinterpretation.

\section{Research context, participants, and sources of data}

This paper comes from a larger ethnographic study of English language learners (ELLs) in a prekindergarten classroom in the United States. The prekindergarten 
classroom was in a city located in the former "Rust Belt," where the last great wave of immigration took place nearly a century ago when the steel industry was booming. Since then, with the collapse of local steel production, the city had become "mostly white, slow growing" (Frey 2000: 21) and decidedly English-speaking. However, with a low cost of living, the city had more recently become a good place for resettling refugees. The classroom I visited opened in fall 2012 (the start of my data collection) to accommodate the growing number of resettled refugee families with young children in the neighborhood. The two teachers - white English speakers, both old enough to have adult children - had many years of collective experience with young children, but were new to teaching ELLs. The children in the class, ages three and four, came from two primary language backgrounds, English $(n=6)$ and Nepali $(n=10)$, while one student spoke Turkish at home. Two of the Nepali-speaking students also spoke some English, but the other eight and the Turkish speaker were almost complete beginners. The study followed students one full day per week across the school year, tracing the joint emergence of their social positioning and second language development. During my time in the classroom, I observed/participated, took field notes, and video recorded for around 2 hours per visit, for a total of 162 contact hours and 40 hours of video. I also interviewed teachers, parents, and students. The general claims that I make in this paper as to the social context surrounding the transcripts presented are therefore grounded in prolonged contact with students and teachers, as well as larger analysis about language learning and classroom social structure. The transcripts themselves come from video, audio, and field notes.

\section{Legitimate misunderstanding and repair}

Because strategic misunderstanding capitalizes on the structure of legitimate misunderstandings, I begin with a review of how basic misunderstanding and repair work. I discuss how this extends to young children and provide an illustrative example from the classroom in question. I then explain a second approach to dealing with misunderstanding that teachers and children used in this classroom, and provide a theoretical account of both kinds of clarification. This framework for how misunderstanding, clarification, and repair work will allow me to show exactly how strategic misunderstanding poaches on this framework. 


\subsection{Legitimate misunderstanding and repair: A brief review}

Researchers interested in communication have long studied misunderstanding as a path to understanding both how smooth communication works as well as how misunderstandings occur and are then managed by interlocutors (Humphreys-Jones 1986). Some of these accounts have aimed to create taxonomies of types of misunderstandings, based on various aspects or features, such as the level of language at which they occur (phonology, semantics, etc) (e. g. Banzanella and Damiano 1999), or how aware participants are, given the underlying reasons for the misunderstanding (e. g. Coupland et al. 1991). At the same time, many of these analyses of misunderstanding - particularly those from the conversation analytic tradition (e. g. Schegloff 1987) - also provide detailed accounts of how misunderstandings unfold, are noticed, pointed out, and addressed.

By all accounts, misunderstanding/repair sequences begin with someone noticing the trouble. (Although of course, misunderstandings may occur without anyone noticing, these do not involve repair or clarification sequences and thus are less relevant for our purposes here.) In what Schegloff et al. (1977) called "other-repair" and Hirst et al. (1994) called an "other-misunderstanding," a hearer notices trouble - that she has not heard clearly, perhaps, or that what she has heard does not make sense within the conversation - and asks for clarification right away ("Pardon?" or "Did you say bees?"). The speaker may then clarify, constituting what Schegloff (1992) called a "third position repair": the first position was the "trouble spot" (Schegloff et al. 1977), the second position was the request for clarification, and the third is the repair ("No, no, beads"). Third position repair can be also initiated by the original speaker, as a "self-misunderstanding" (Hirst et al. 1994). This occurs when the original speaker (position 1) notices that his interlocutor's reaction (position 2) is incongruent with what the speaker meant and infers from this logical breakdown that interlocutor misheard or made the wrong interpretation (Banzanella and Damiano 1999). In both cases, after the misunderstanding-repair sequence is complete, the speakers resume the conversation.

Repairs may also occur in the fourth position, if speaker 2 notices an incongruence between her second position interpretation and speaker 1's subsequent third position turn, or in subsequent positions, if misunderstandings take several turns to notice, or if it takes several turns to navigate to the repair sequence. The third position repair - trouble spot (1), clarification request (2), 
repair (3) - is the most common, however (Banzanella and Damiano 1999), and is the basis for the discussion in this paper.

\subsection{Preschoolers doing legitimate misunderstanding and repair}

Work that has approached children and misunderstanding from a developmental perspective has found that preschoolers are quite capable of doing this kind of clarification and repair work. Children as young as 2;6 (2 years, 6 months) are able to notice misunderstandings in conversation, both on their part and by others, and are able to respond to them, through self-repair as well as through requests for clarification (Garvey 1984; Golnikoff 1993; Forrester and Cherington 2009). Although there has been some debate as to what very young children's motivations are for repairing misunderstandings Shatz and O'Reilly (1990), for instance, argued that children were more likely to initiate repairs when making requests than assertions - there is not debate over whether they can engage in them at all. And while much of the research on young children and repair examines children speaking with adults, other work also shows children engaging in repair with one another. In one study of spontaneously occurring conversation between 2;8- to 3;6-year-old peers, Aviezer (2003) found that "young children are sensitive to conversational breakdown and recognize different kinds of communicative failure as well as being able to initiate effective clarification procedures as an invitation for others' repair" (134). Although older children engaged in clarification sequences more frequently, all of the children in his study recognized misunderstandings and engaged in repair, particularly in clarification sequences. From a developmental perspective, therefore, the students who produced the conversations in the present paper (ages 3;6 to 4;10) would be able to engage in negotiation of misunderstandings and repair. As the following example illustrates, that is indeed the case.

\subsection{Preschoolers doing legitimate misunderstanding and repair: An example}

In this example, the interlocutors are a 4-year-old Nepali speaker, Kritika, and her English-speaking teacher, Lucia. The interaction began as Lucia overheard 
three students speaking in Nepali about a drawing. Hoping to encourage their use of English, she asked the students what they were saying. Kritika answered, but Lucia did not understand her response, so Lucia and Kritika engaged in a clarification and repair sequence. The multimodal transcript highlights Kritika's use of multiple modes to help Lucia arrive at her intended meaning. The shape and direction of the over-image text show the intonation of Kritika's speech. The captions show the timestamp and describe the action taking place.

\section{Example 1}

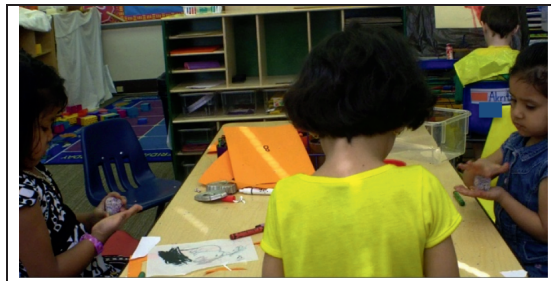

Kritika (left) and two other Nepali speakers are at the art table. Teacher Lucia is out of camera view, to the right, preparing lunch at the next table.

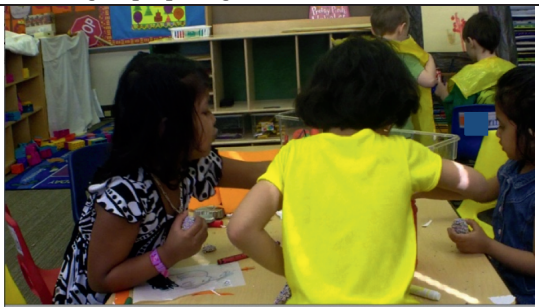

25:40 Kritika says something in Nepali as she reaches for the drawing.

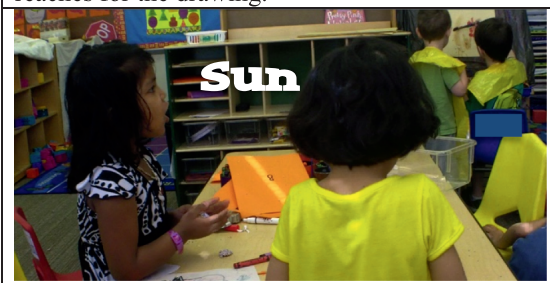

25:43 Kritika answers, "Sun," but her pronunciation (/spn/) is closer to the "o" in "song" than the "u" in "sun" (/sən/)

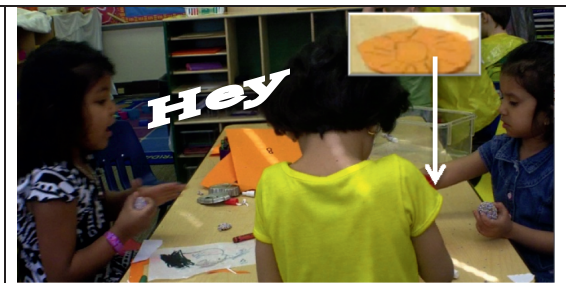

25:39 The student on the right picks up a drawing of the sun (see inset) that Kritika made earlier. Kritika objects loudly.

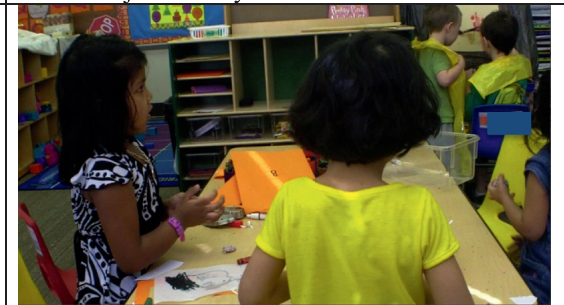

25:42 Teacher Lucia overhears and asks, "What does that mean Kritika?"

25:44 Lucia, off camera: "Huh? Song?" 


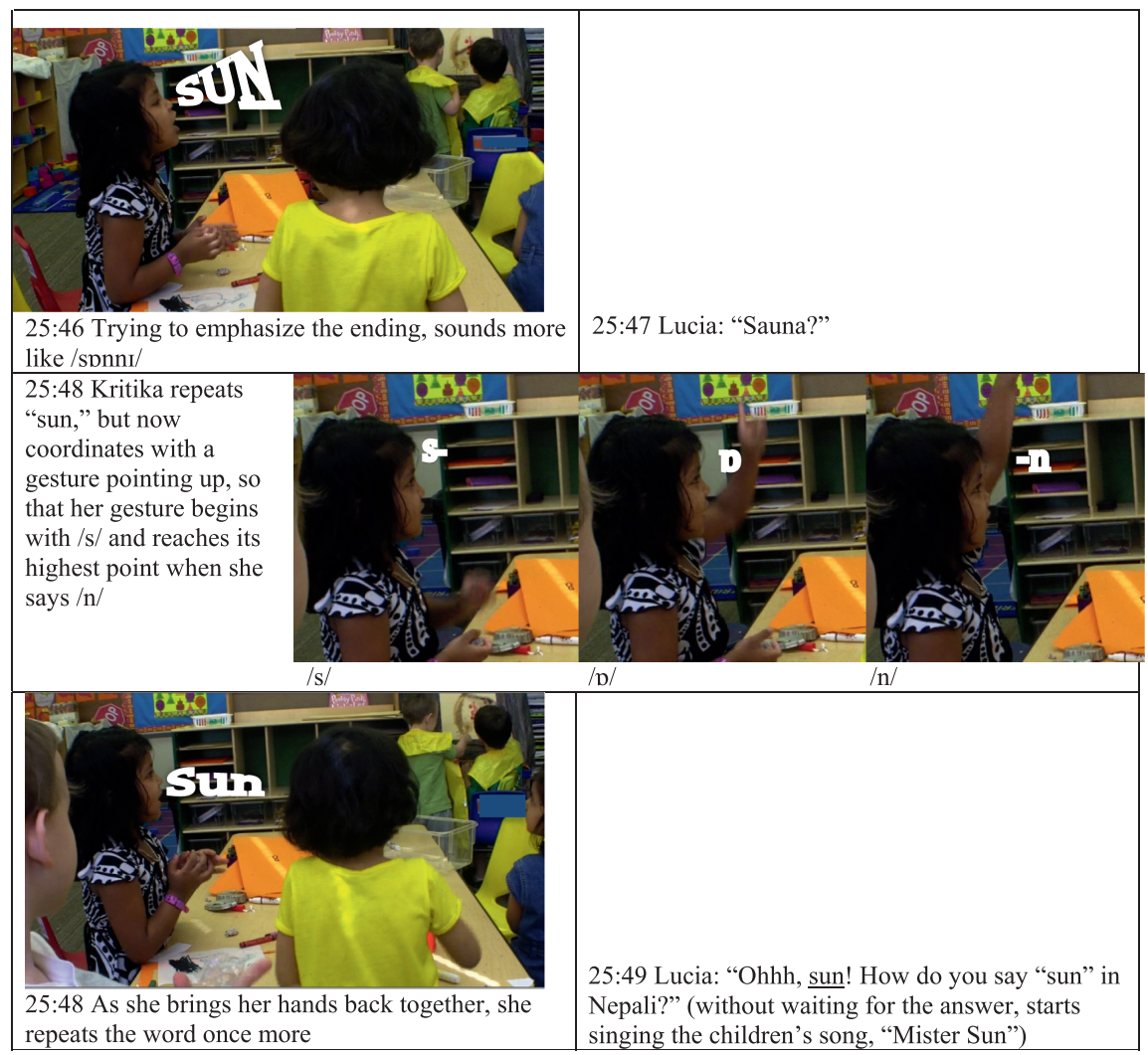

This example shows the kind of misunderstanding/clarification/repair sequence outlined above, in which one interlocutor notices that she may have misheard, she checks with the speaker, the speaker attempts to clarify, and they go back and forth until understanding is reached. Interactions like this one show students and teachers knowing how to "do" - jointly produce - misunderstanding/ repair routines. These kinds of misunderstandings/repairs exemplify the cooperative spirit assumed in much work on miscommunication in general and on intercultural miscommunication in particular: Misunderstandings happen, but with enough goodwill and effort, communication can proceed.

\subsection{Repairing misunderstanding through third party interpretation or "speaking for"}

A different way of resolving misunderstanding in this classroom involved the use of a third, mediating interlocutor. This practice originated with the teachers: 
Because of the makeup of the classroom, at the start of the year, the teachers had significant trouble understanding many of the students, and thus relied on peers who already spoke some English to help by interpreting, or clarifying what a student said. This did not necessarily mean translating from Nepali to English. Often it meant simply repeating what a student had said, but in clearer English. Like the third position repair sequences outline above, these interactions had a routine format. A student would speak to the teacher (position 1), the teacher would realize she did not understand and would call another student to help (position 2), and the interpreter would clarify (position 3). The position 2 requests for clarification took a routine format: "Dinesh, what's Monal saying?”; "Dinesh, help me out,”; “Dinesh, I can't make out what Maiya is saying. Can you help me?” (Field Notes, October 10, 2012). The student, in these cases Dinesh, would typically reply in position 3 in a format for reporting speech - "She's saying 'More pineapple!'” - and the interaction would continue. (I label these examples collectively Example 2).

The role of interpreter was a powerful one, particularly when it served as gatekeeper (for instance, of access to the teachers), and sometimes students stepped into the interpreter role of their own accord, as Kritika did in the following interaction. This conversation took place just after morning circle time (the time when the whole class met to talk about the day ahead), as Hande, a Turkish speaker, was attempting to tell the teacher where she intended to play for the next hour of the day.

\section{Example 3}

1 Lucia: Hande, where are you going?

2 Hande: (points toward the dress up/ play kitchen area, known as

3 "housekeeping")

4 Lucia: Housekeeping?

5 Hande: No. (says something unintelligible, points up and over)

6 Kritika: (standing next to them) Sand!

7 Lucia: Did she say sand?

8 Kritika: (nods)

9 Hande: No (stands on toes to point up and over)

10 Lucia: Go 'head Hande, just show me.

11 Hande: (goes to sand)

12 Lucia: (smiles, nods at Kritika)

November 19, 2012 (Field notes)

Although Hande did not acknowledge it herself, Kritika correctly interpreted where Hande wanted to play. This was not lost on Lucia, who smiled and 
nodded knowingly at Kritika in line 12, after observing Hande's choice. Whether the interpreter was invited by the teacher or took up the role on her own, her responsibility was to convey the words of a student who was unable (or who the teacher saw as unable) to engage in the clarification sequence herself.

\subsection{The participation framework of Speaking For}

What unites the cases of two-party clarification/repair and three-party clarification/repair is that both involve the act of Speaking For another person. In the "sun" clarification sequence (Example 1), for instance, Lucia repeated what she believed she heard; in the Dinesh examples (Example 2) and the "sand" example (Example 3), the interpreter recast what he believed he heard in a way that clarified it for the original, intended hearer. In both cases, this voicing of another speaker's words somewhat complicates the typical notion of speaker, a person whose words represent his own ideas and intentions, and hearer, the intended audience for those ideas.

Goffman (1981) deconstructed the roles of speaker and hearer in ways that are useful here. He argued that "speaker" and "hearer" do not address all of the ways of being a speaker and hearer, particularly in multi-party interactions. Rather than "hearer", he proposed to distinguish between official audience members ("addressee(s)", "unaddressed intended hearers", "intended hearers who are not listening”, etc.) and unofficial hearers (such as "overhearers", "eavesdroppers", "bystanders"). He also dissected the role of speaker into three "production formats": animator (the mouthpiece for the words), author (the creator of the words being spoken), and principal (the one whose interests or beliefs are conveyed by the words being spoken). Goffman explained that all three production formats can be united in one person (as when Kritika declared, "Sun"), or they can be distributed among different people (as when Kritika said "sand," animating Hande's words). These ways of being speaker and hearer, when configured in various arrangements, form different participation frameworks. The participant framework of Speaking For, for instance, was a common one in this classroom, and was invoked specifically as a way to repair misunderstanding.

To revisit the examples of interpretation (Examples 2 and 3) then through Goffman's production formats, Maiya (looking for more pineapple) and Hande (looking to play with the sand) were the authors, animators, and principals behind their original utterances. When they ran into trouble, however, their words were re-animated by another speaker for clarification. Dinesh said "She's saying 'More pineapple!” and Kritika said, simply, "Sand.” Dinesh and Kritika 
were not the authors of the words, nor were they invested, as principals, in the message the words conveyed; they only served as their animators. In terms of recipient formats, Dinesh and Kritika, although they certainly heard the original utterances, were not original addressees. Dinesh was brought in as an unaddressed (but intended) hearer, while Kritika was a bystander who stepped in of her own accord. In both cases, they functioned as a stand-in understander (for an addressed non-understander) and then a helpful mouthpiece.

Even in the case of a two-party interaction, we can understand the clarification sequence as a change in participant framework, from standard conversation in which speakers function as animators, authors, and principals of their own utterances and hearers function as official addressees - to a Speaking For framework, in which one person becomes an animator for the other in order to clarify what was said. In Example 1, for instance, when Teacher Lucia asked, "Song?" and then "Sauna?," in each case, she was animating (what she thought were) Kritika’s words.

\subsection{Speaking For as double-voiced discourse}

As helpful as Goffman's categories are for understanding each participant's role in these misunderstanding/repair sequences, this dismantling of speaker and hearer also risks oversimplification. Although Speaking For indeed involved animating another person's words, in another sense, it also meant issuing a response to those words and, in that response, a social positioning. ${ }^{1}$ In the case of the "sun/sauna" misunderstanding, for instance, when Lucia said "sauna," she was not only re-animating what she thought Kritika said, she was also responding that she had not understood, but that she wanted to understand.

1 The idea of positioning (c. f. Davies and Harré 1990) refers to being located, through language, as a particular, socially recognizable kind of person. While a speaker may resist being positioned in a certain way, power relations may be such that one's own positioning is not always in one's control. While positioning can certainly be intentional, and even strategic, it can also be unintentional, or a "side-effect." For instance, if a man offers to lift a heavy load for a woman, he may intend simply to be helpful, but, because positioning is always relational, by positioning himself as strong and helpful, be also positions the woman as weak and in need of help. The same utterance, therefore, can create multiple, simultaneous positionings, which are not always directly related to a speaker's intentions. This is important to note for two reasons. The first is that if positioning were to reside in intent, speakers would always have an alibi or an escape: “I didn't mean to...” The second is that an analysis of positioning allows a discussion of language and power even when it is not possible to ascribe intent, as with very young speakers. The strength of "positioning" as an analytic construct lies in its ability to deconstruct power relations that speakers themselves may not be able to articulate. 
Additionally, in making this response, she positioned Kritika as a speaker who was difficult to understand, but also worth understanding, despite it taking a bit of work. Speaking For can therefore be seen as what Bakhtin (1981) called double-voiced discourse, or language that "serves two speakers at the same time and expresses simultaneously two different intentions" (324). In the original focus of Bakhtin's theory of double-voiced discourse - the novel - the two voices are those of the speaking character and of the author, expressing both the character's intention and the author's. In the examples here, the two voices belong to the author of the original words and to their re-animator. Thus, when Kritika told the teacher, "Sand," on Hande's behalf, she not only animated Hande's words and shared Hande's intention with the teacher, she simultaneously conveyed her attentiveness and helpfulness and positioned herself as a capable interpreter, able to understand and to convey a message more clearly than the original speaker. She also, by the very act of Speaking For (and whether she meant to or not), positioned Hande as a less capable communicator and someone in need of assistance.

\subsection{Who could speak for whom?}

Together, the concepts of participant framework, with accompanying production formats, and of double-voiced discourse provide a way to understand why not all students could take on all of the roles in the Speaking For frame. While anyone technically could repeat another's words, animating those words required others to step into the accompanying roles of spoken-for-author and of-addressee-accepting-the-interpretation, and to acknowledge the animator as a legitimate interpreter. In the Dinesh examples (Example 2), it was the teacher who invited Dinesh into the role of interpreter, accepting the addressee role for herself. Additionally, students like Maiya and Monal accepted the help, and with it the positioning that came with each double-voiced act of Speaking For: The first voice was that of the Monal, for instance, looking to convey his request, the second was that of Dinesh, positioning himself as helpful, useful, and, importantly, as a more competent English speaker than Monal. Thus, the success of the entire operation depended on whether the addressee (here, teacher) saw the interpreter (here, Dinesh) as a more competent speaker than the spoken-for student (Monal or Maiya). Thus, the power to speak for another student was a relational power. It was not something that a student always possessed, nor did it depend on an objective measure of English proficiency; instead, a student's ability to successfully claim the role of interpreter depended on his competence, first, relative to the spoken-for student and, second, in the eyes of an addressee. 
As such, not all students were able to successfully take up the interpreter role, as illustrated by the following transcript.

\section{Example 4}

The teacher is coming around to the lunch tables with a carton of milk, offering to pour some for the students.

1 Anita: (says something in Nepali to Pooja, ending with paani [water])

2 Teacher: Anita, milk?

3 Pooja: She wants water.

4 Teacher: (to Pooja) No, we'll let her talk.

$5 \quad$ (to Anita) What would you like to drink?

6 Anita: (whispers) Water

May 6, 2015 (Video)

In refusing to engage in the participant frame of Speaking For that Pooja invoked, the teacher rejected Pooja's double-voiced speech on both levels: as animation of Anita's words (prompting Anita to speak for herself) and as a claim to Pooja's relative competence and Anita's relative incompetence as English speakers. Despite Anita's willingness to be spoken for, it was the addressee in this case, the teacher, one of the listeners with the most power to judge competence - whose ratification of the framework really mattered. In this classroom then, one kind of symbolic power was the power to invoke and draw others into a desired participant frame.

\section{Strategic misunderstanding}

Having established what legitimate, two- and three-party misunderstanding/ clarification sequences looked like in the classroom, and how they functioned in terms of participation frameworks, positioning, and power, it is now possible to explore strategic misunderstandings, which function precisely because they masquerade as legitimate misunderstandings.

Hinnenkamp (2003) saw misunderstandings - legitimate or otherwise - not as facts, but as interactional achievements that only occur with recognition and action on the part of one or more interlocutors, Part of being a capable interlocutor, therefore, is knowing how to "do" misunderstandings: how to recognize them and draw attention to them, how to initiate repairs and execute them, and how to navigate back to the main conversation. Hinnenkamp proposed that this knowledge allows interlocutors to use the knowledge strategically: Knowing how to navigate a misunderstanding sequence gives one the potential to 
"abuse the misunderstanding sequence by extending it, or [to know] how a misunderstanding is creatively and playfully exploited" (70). Hinnenkamp differentiated, however, between "knowing how," as in knowing how to "do" misunderstandings, and "knowing that," as in knowing that when I declare not to have understood someone or that she has not understood me, it makes her seem lacking in some capacity, or perhaps buys me more floor time, or might even get a laugh. When an interlocutor uses misunderstandings to intentionally accomplish one of those consequences, it is not a true misunderstanding but a strategic misunderstanding, or "the analytic and conversational exploitation of a misunderstanding event” for one's own purposes (71). Hinnenkamp also called these parasitic misunderstandings, since they take the shape of genuine misunderstandings, but are "counterproductive to clarification and solution" (71).

Hinnenkamp illustrated this kind of "misunderstanding" with close conversation analysis of a conversation between an international group of speakers attending a workshop in Germany. A Taiwanese speaker, "B”, described how, in Taiwan, if a meal is not warm, it does not count as a true meal. The conversation continued, and the speaker reiterated that when his wife, also Taiwanese, has not eaten something warm, she has not "eaten" at all: "Meine Frau, wenn sie nicht warm isst, sie hat nicht gegessen” (71) [My wife, if she has not had a warm meal, she just hasn't eaten] (72, Hinnenkamp's gloss). After he repeated this, another speaker, "H”, interjected: “Ach so, ich hab verstanden, wenn sie nich warm is, ${ }^{2}$ dann sie hat sie nicht gegessen” (72, emphasis in original) [I see, I'd understood, if she isn't warm, then she hasn't eaten (72, Hinnenkamp's gloss).] This was followed by uproarious laughter by many in the group, although not by $\mathrm{B}$, the original speaker.

In this example, H's purported "misunderstanding" rests on a German pun and slang. In German, "sie isst" [she eats] sounds the same as "sie ist" [she is], so that the phrase "Sie /Ist/ warm" could be interpreted not as, "She eats warm (food)," but as "She is warm" (which is also slang for ready for sex). Hinnenkamp argued, however. that there was no real way for $\mathrm{H}$ to have misunderstood, since all prior turns had been about eating and meals, and that $\mathrm{H}$ was instead exploiting a particular misunderstanding format ("Ohhh, I had understood x, but really you meant y") to make a joke at the expense of poor B. In making this joke, $\mathrm{H}$ not only got a laugh, but also highlighted that $\mathrm{B}$ had been unclear and brought B's private life and wife into the conversation in a way that B clearly had not intended. Thus, H's joke-masquerading-as-misunderstanding was a strategic

2 Really, "ist" ("is") in German. Hinnekamp explains that the speak dropped the "t" to help accentuate the difference between the homophones isst ("eats") and ist ("is"). 
and parasitic use of the misunderstanding format, seriously threatening B's face and scoring conversational points for $\mathrm{H}$, indicated by the long laughter by the group.

\subsection{Strategic misunderstanding, plus power and positioning}

What Hinnenkamp's analysis (or any other grounded only in linguistic data) cannot answer, however, is who can successfully use these strategies, when, and to what broader effects. Answering these questions requires looking beyond a single transcript to the larger social field in which the interaction occurred, including social relations, which are always also power relations. Deborah Cameron's (1998) work - also about misunderstandings that are not really misunderstandings - introduces power into the equation. Cameron's work on communication across genders began from a similar premise to Sarangi's: that misunderstandings in cross-gender communication cannot automatically be assumed to be the result of gender difference, and while there are certainly examples of true misunderstandings across genders, many of the "misunderstandings" between men and women are not explainable by some inherent difference in how men and women speak, but by conflicts in interest.

One of Cameron's examples of misunderstanding-that-is-really-conflict came from a magazine article containing advice for women about how to communicate at work. It gave the example of a female boss saying to her male subordinate, "Would you like to finish that report today?", and later returning to find it unfinished. When the boss admonished the employee, he became defensive, saying that if he had to finish today, she should have said so. The advice column then explained that by being more direct (i.e. more like a man), and thus making it clear that the report must be finished that day, the boss could have avoided the misunderstanding. Cameron argued, however, that in the context of a workplace, where one's personal preferences are generally less relevant than carrying out one's duties, the man should have had no trouble inferring that his boss was not asking about his taste in work tasks, but requesting that he finish the report. Cameron provided two possible alternative interpretations: Either the man pretended to misunderstand ("misunderstood"), using the form of her indirect request as a cover and an alibi; or the man genuinely misunderstood her request as a suggestion, the result of a general refusal to see a woman as someone in a position to give him orders. Importantly, either way, his response evidences a dispute over power relations between employee and boss, male and female. In a different conversation, in which there was no conflict over power and authority, the man would likely have no trouble interpreting the question, 
"Would you like to finish that report today?”, as the strong-suggestion-vergingon-order that it was meant to be. As Cameron put it:

The same person can behave very differently depending on who he or she is talking to, from what position, and for what purpose; the utterance which is 'misunderstood' by an individual in one situation may be treated as perfectly transparent by the same individual in another. (451)

This is because all communication creates a frame in which speakers and hearers inhabit particular social positions (e.g. "I am the kind of person who can make requests like this and you are the kind of person who will carry them out"). And while the act of speaking sets up the frame and positions, the act of understanding is a decision whether or not to accept them. For Cameron, one of the ways to resist an undesirable frame or position is to "misunderstand:"

[L]aying claim to a particular intention or interpretation can function as a strategic move in a game of power and resistance. What is commonly called 'misunderstanding' may often be better analyzed as a kind of conflict; at bottom, conflict about the social positioning that is always implicitly presupposed when one person addresses another. (452)

From this perspective, a misunderstanding might be a refusal on the part of a hearer to participate in the conversational frame being set up by the speaker, or to be positioned in the way that the speaker's utterance, if understood as it was intended, would position him.

In a sense then, strategic non-understanding, or refusing to comprehend in any way at all, could in the most basic way accomplish a rejection of a speaker's positioning of a hearer (a woman does not turn when a man calls "baby" across the street; a preschool student looks blankly at another who says, "You took my toy.") Strategic misunderstanding is slightly more complex in that it not only refutes the speaker's proposed positionings, but offers alternate ones. In the "misunderstanding" between the boss and employee, for instance, the employee's interpretation of the request (as a question) offers a different interpretation not only of the words, but also of the relationship between the speakers, as if to say, "You are not someone who gives me orders. I am not someone who has to take your requests too seriously.” Thus, while Hinnenkamp interpreted H's false misunderstanding as a way to get the floor and get a laugh at B's expense, we might also understand it as a conflict over positioning. Perhaps $\mathrm{H}$ did not see himself as the kind of stumbling, backtracking, clarification-seeking non-native speaker that he perceived $B$ to be. Proposing a false misunderstanding, then, not only got a laugh, but also positioned him as facile with German and thus unlike B. 
Armed now with Hinnekamp's and Cameron's theories, as well as a theory of how legitimate misunderstanding and repair worked in this classroom, I now turn now to one of the troubling interactions that looked, at first glance, like a true misunderstanding and interpretation sequences but that, on closer inspection, was not.

\subsection{Preschoolers doing "misunderstanding" and (mis)interpretation}

The interaction involved Hande (age $4 \frac{1}{2}$ ), the sole Turkish speaker in the class and one of the students that the teachers worried about most. Throughout the year, peers saw Hande as a dispreferred playmate and teachers saw her as somewhat of a loner (Bernstein 2014). Unlike the Nepali speakers, who could showcase their interactional and social competence in their L1, Hande could only interact in English. Although in the end this may have helped her grow more in terms of vocabulary and utterance complexity than the other ELLs (Bernstein 2014), she struggled socially, and this led the teachers and classmates to see her as a less-than-competent communicator. The other participants in the interaction were Tommy (age 31/2) a white, male, English speaker and Lucia, the teacher. The interaction occurred in April of the school year, at snack time, where Hande was sitting next to Tommy. Midway through snack time, over the course of several minutes, Tommy took all of the orange slices from the shared serving bowl, squeezed them one-by-one into his milk, and then soaked his napkin in it. As he wrung his napkin onto his plate and began lapping it up like a cat, Hande reached for an orange slice and found that the bowl was empty. Looking at the pile of the discarded orange peels and wet, balled-up napkins in front of Tommy, who was still licking milk and juice from his plate, Hande, appalled, called to the teachers to tattle on him. Researchers who have studied tattling have shown how children use it to resolve conflict and restore the moral order (Danby and Theobold 2012; Kyratzis 2004) of the classroom, particularly when students do not have the resources, linguistic or otherwise, to resolve it themselves (Cekaite 2012). This transcript begins with just such a tattle and with Teacher Lucia approaching the table.

\section{Example 5}

1 Hande: (pointing) Look she did her paper this! Tommy this her paper did this! She did her paper all this! Tommy did all milk. Miss Lucia! Miss Lucia!

3 Lucia: (comes closer) 
4 Hande: No more in here liquid! She's there. All mixed up. And she's eating. 5 Tommy all milk. She drink it. Now she drink it! No more orange!

6 Lucia: Alright thanks, Hande.

7 Tommy: (interrupts) No, I'm NOT a girl. I a boy!

8 Lucia: Tommy, finish your snack.

9 Tommy: She called me a girl!

10 Lucia: She gets mixed up, that's all. It's okay.

11 Tommy: (to Hande) YOU called me girl. (to Lucia) SHE did. She DID that to 12 me. (crossing arms across chest)

13 Hande: I called you a boy.

14 Lucia: (to Tommy) Alright sweetheart, want to eat some of your bread and 15 jelly?

(Audio recording and field notes, April 15, 2014)

At first reading, I flagged this conversation as a legitimate misunderstanding, because neither the teacher nor Tommy seemed to understand what Hande was trying to convey - that Tommy had made a huge mess and taken all of the oranges. Yet, Hande's tattle was quite complex and complete, if non-standard, and the evidence of the mess - soaked napkins, discarded orange peels, milky orange juice running down Tommy's chin - was visible. Thus it ought to have been quite clear to Tommy and Lucia what Hande was saying. Cameron's perspective can help to explain what happened and how Tommy accomplished it.

A successful tattle involves drawing the teacher in as an objective party who neutrally hears out the conflict, through questions like "What happened?", and then acts as judge and restorer of moral order through socializing questions, such as “How come X?" or "Why did you X”? (Cekaite 2012; Sterponi 2003). In this case, Hande's tattle in lines 1 and 2, which opened the interaction and continued into lines 4 and 5, did not cast Tommy in a very favorable light. The conflict of interests here is clear: If Hande's message were to be understood as a tattle, Tommy would likely be punished; if Hande's message was not understood as a tattle, Tommy might avoid punishment. In terms of positioning, Hande's tattle would position her as a reliable source of information and a competent student - someone who knew how to appropriately behave at snack time - in contrast to Tommy, a misbehaver, and thus a less competent student. In line 6, the teacher began to take up the tattling framework, neutrally thanking Hande for the information and taking in the scene.

Tommy, aware of the consequences of Lucia's understanding, made a strategic move. In line 7 , he presented a counter-tattle based on a strategic misunderstanding of what Hande said: That by using the wrong pronoun 
(she, rather than he), Hande had in effect, called Tommy a girl. Suddenly, Hande was in the position of being accused, rather than accusing. Additionally, Tommy, in "failing” to understand Hande's utterance, positioned her as linguistically incompetent (or worse, too stupid to know the difference between boys and girls), undermining her authority as speaker and thus delegitimizing her tattle. While the teacher (line 8) did not ratify Tommy's new frame, she did not contradict it either, nor did she participate further in the tattling frame that Hande proposed. Tommy, still not satisfied that the teachers understood his "misunderstanding" of Hande's utterance, moved in line 9 into the reported speech formula of (a false) speaking for. In a strategic (mis)interpretation, Tommy spoke for Hande using words that Hande never actually said, attempting to pass them off as an animation, rather than an authoring, thus roping Hande into being the principal behind them. In a parasitic double-voicing, he voiced his interest (highlighting how he was wronged, but also showing himself to be a reliable source, unlike Hande) and purported to voice hers as well (calling him a girl), when in reality his utterance presented only his view.

In line 10, there was a shift, as Lucia was finally drawn into the frame that Tommy set up. Although Lucia tried to defuse the situation, assuring Tommy that Hande did not really believe he was a girl and did not mean to call him one, in doing so, Lucia also positioned Hande as someone who did not know what she was saying, or a confused English learner. Lucia thus ratified a frame in which Hande's tattle might be unreliable as well. Tommy persisted in his claim, and although, in line 13, Hande resisted his positioning of her as a confused or inaccurate speaker, to do so she was forced to abandon her own conversational frame and to enter Tommy's, in which she and her credibility, rather than Tommy and his mess, were on trial. In the end, Lucia tried again to diffuse the situation - this time through distraction with bread and jelly - leaving Tommy unpunished, the orange bowl empty, and the power differential between Tommy and Hande intact. By accepting Tommy's strategic and decidedly parasitic "misunderstanding” and (mis)interpretation as true misunderstanding and interpretation, Lucia underlined that, as an English speaker, Tommy had the power to redefine the situation and to be taken seriously in a way that Hande, a "mixed up" English learner, did not.

\section{Discussion}

The extracts presented here - the legitimate misunderstandings as well as the strategic one - illustrate that these preschool students were keenly aware of how to do misunderstanding. The strategic use of misunderstanding on the part of 
Tommy highlights that this knowledge extended beyond what Hinnenkamp called "knowing how" - knowing how misunderstandings work - to "knowing that" - knowing that misunderstandings have particular conversational effects. This "knowledge that" enabled Tommy to use misunderstanding to accomplish very specific conversational aims.

The examples (both legitimate and strategic) also make plain that misunderstanding and repair are not just conversational tools with conversational effects, but social tools with social effects, particularly in terms of how they position participants as competent or incompetent interlocutors. In a legitimate misunderstanding sequence between two speakers in an egalitarian relationship, if a hearer asks for clarification, the message is: "One of us has dropped the ball here - either me as a hearer or you as a speaker - but whatever you have to say, it is worth the effort to figure it out." When the two speakers do not enter the interaction on equal linguistic footing, however, (as in the case of an ELL and an English speaker, for instance, in a classroom where English is the official language and the language of learning and authority), the social consequences of a misunderstanding are not equal either. If an ELL says, "What?," she might be taken to mean "I have a hard time understanding," and if someone says, "What?" to her, it may come mean "You are hard to understand."

Thus, when Lucia initiated the misunderstanding sequence with Kritika, whether she meant to or not, she positioned Kritika as hard-to-understand. Yet, simultaneously, her request for clarification positioned Kritika as having something important to say and as worth understanding. And by engaging in clarification with Kritika herself, Lucia made clear that she thought Kritika could eventually convey her meaning on her own. Contrast this with the interpretation sequences in Examples 2 and 3: In these sequences, the teacher initiated a misunderstanding sequence (positioning Monal, Maiya, and Hande as hard-tounderstand) and a clarification (positioning them as worth understanding), but unlike the "sun" example, she looked not to Monal, Maiya, and Hande, but to an interpreter, implying that each student's utterance was not just hard for her to understand, but impossible, and that the students themselves were not capable of clarification. Each interaction, then, served as what Jiang and Zhu (2012) referred to, after Auer (1984), as an "ascription of incompetence." Each misunderstanding sequence (the interpretation sequences to a greater degree than standard clarification) called into question the ELL's ability as a speaker, positioning him/her as linguistically less-than-capable. Yet while these interactions ascribed the students with varying degrees of linguistic incompetence, each sequence also served as what might be called an ascription of "comprehension-worthiness," or the positioning of the students as worth understanding or worthy of comprehension. 
Tommy's strategic misunderstanding, on the other hand, capitalized on the first ascription, and cannibalized the second, ascribing incompetence to Hande without any of the effort to clarify and thus to ascribe comprehension-worthiness. Tommy drew on already unequal power relations - between English-speaker and English-learner, but also perhaps boy and girl, American and immigrant - to accomplish his immediate aim of evading punishment by distracting Lucia from the framework Hande sought to bring her into, in which Lucia punished Tommy and thus restored the classroom moral order. However, his successful strategic use of the misunderstanding and interpretation frames also served to reinforce Hande's position as incompetent and to reinscribe existing power relations between Hande and himself.

\section{Conclusion}

In this paper, I have presented a framework for beginning to understanding why, how, and to what effects preschool students might use strategic "misunderstanding" and (mis)interpretation in intercultural classroom interaction. I have shown that intercultural-ness, per se, did not cause Tommy and Hande's "misunderstanding," but that Tommy was able to exploit the misunderstanding and Speaking For frames as well as the power imbalances that were byproducts of the intercultural make-up of the class. I suggest that if children as young as three- and four-years-old can exploit their knowledge of misunderstanding and of power relations to strategic conversational and social ends, strategic "misunderstanding" and (mis)interpretation are unlikely to be conversational rarities. Asking who benefits from them and what kinds of conflicts are at their root in a variety of contexts may push the study of intercultural communication (and miscommunication) in new ways.

\section{References}

Auer, Peter. 1984. Bilingual conversation. Amsterdam: John Benjamins.

Aviezer, Ora. 2003. Bedtime talk of three-year-olds: Collaborative repair of miscommunication. First Language 23(1). 117-139.

Bakhtin, Mikhail M. 1981. The dialogic imagination: Four essays (M. Holquist \& C. Emerson, Trans.). Austin, TX: University of Texas Press.

Bazzanella, Carla \& Rossana Damiano. 1999. The interactional handling of misunderstanding in everyday conversations. Journal of Pragmatics 31(6). 817-836.

Bernstein, Katie A. 2014. Learning English as an L2 in PreK: A practice perspective on identity and acquisition. Berkeley, CA: University of California at Berkeley dissertation. 
Cameron, Deborah. 1998. 'Is there any ketchup, Vera?': Gender, power and pragmatics. Discourse \& Society 9(4). 437-455.

Cekaite, Asta. 2012. Tattling and dispute resolution: Moral order, emotions and embodiment in the teacher-mediated disputes of young second language learners. In M. Theobald \& S. Danby (eds.), Disputes in everyday life: Social and moral orders of children and young people, 165-191. Bingley, UK: Emerald Group Publishing Limited.

Coupland, Nikolas, John M. Wiemann \& Howard Giles. 1991. Talk as "problem" and communication as "miscommunication": An integrative analysis. In N. Coupland, H. Giles \& J. M. Wiemann (eds.), “Miscommunication” and problematic talk, 1-17. Newbury Park, CA: Sage.

Davies, Bronwyn \& Rom Harré. 1990. Positioning: The discursive production of selves. Journal for the Theory of Social Behaviour 20(1). 43-63.

Fail. (n.d.). http://www.merriam-webster.com/dictionary/misunderstand (accessed June 1, 2015).

Forrester, Michael A. \& Sarah M. Cherington. 2009. The development of other-related conversational skills: A case study of conversational repair during the early years. First Language 29(2). 166-191.

Frey, William H. 2000. The new urban demographics: Race space \& boomer aging. The Brookings Review 18(3). 20-23.

Garvey, Catherine. 1984. Children's talk. Cambridge, MA: Harvard University Press.

Golinkoff, Roberta M. 1993. When is communication a "meeting of minds"? Journal of Child Language 20(1). 199-207.

Goffman, Erving. 1981. Footing. In Forms of talk, 124-159. Philadelphia, PA: University of Pennsylvania Press.

Gumperz, John J. 1978. Conversational analysis of interethnic communication. Presented at the SEAMEO Regional Language Centre Seminar on Acquisition of Bilingual Ability and Patterns of Bilingualism, Singapore.

Gumperz, John J. 1982. Discourse strategies. New York: Cambridge University Press.

Gumperz, John J. \& Celia Roberts. 1991. Understanding in intercultural encounters. In J. Verschueren \& J. Blommaert (eds.), The pragmatics of intercultural and international communication, 51-90. Amsterdam: John Benjamins.

Hinnenkamp, Volker. 2003. Misunderstandings: Interaction structure and strategic resources. In J. House, G. Kasper \& S. Ross (eds.), Misunderstanding in social life: Discourse approaches to problematic talk, 57-81. New York: Routledge.

Hirst, Graeme, Susan McRoy, Peter Heeman, Philip Edmonds \& Diane Horton. 1994. Repairing conversational misunderstandings and non-understandings. Speech Communication 15(3). 213-229.

Humphreys-Jones, Claire. 1986. An investigation of the types and structure of misunderstandings. PhD Thesis. Newcastle-on-Tyne, UK: Newcastle University.

Jackson, Alecia Y. \& Lisa A. Mazzei. 2012. Thinking with theory in qualitative research: Viewing data across multiple perspectives, 1st edn. New York, NY: Routledge.

Jiang, Yan \& Hua Zhu. 2012. Communicating in a lingua franca: Children's interaction in an international summer camp. Sociolinguistic Studies 4(3). 535-552.

Kyratzis, Amy. 2004. Talk and interaction among children and the co-construction of peer groups and peer culture. Annual Review of Anthropology 33(1). 625-649.

Misunderstand. (n.d.). http://www.merriam-webster.com/dictionary/misunderstand (accessed 1 June 2015). 
Sarangi, Srikant. 1994. Intercultural or not? Beyond celebration of cultural differences in miscommunication analysis. Pragmatics 4(3). 427-438.

Schegloff, Emanuel A. 1992. Repair after next turn: The last structurally provided defense of intersubjectivity in conversation. American Journal of Sociology 97(5). 1295-1345.

Schegloff, Emanuel A. 1987. Some sources of misunderstanding in talk-in-interaction. Linguistics 25(1). 201-218.

Schegloff, Emanuel A., Gail Jefferson \& Harvey Sacks. 1977. The preference for self-correction in the organization of repair in conversation. Language 53(2). 361-382.

Shatz, Marilyn \& Anne W. O'Reilly. 1990. Conversational or communicative skill? A reassessment of two-year-olds' behaviour in miscommunication episodes. Journal of Child Language 17(01). 131-146.

Sterponi, Laura. 2003. Account episodes in family discourse: The making of morality in everyday interaction. Discourse Studies 5(1). 79-100.

Theobald, Marianne \& Susan Danby (eds.). 2012. Disputes in everyday life: Social and moral orders of children and young people. Bingley: Emerald Group Publishing Limited. 